\title{
Uma revisão histórica acerca do conhecimento sobre a sedimentação atual, em ambientes marinhos submersos, do Estado de São Paulo, Brasil
}

\author{
(A critical review about the knowledge of the present sedimentation of the \\ State of São Paulo, Brazil)
}

\author{
Marcelo Rodrigues; Michel Michaelovitch de Mahiques; Moysés G. Tessler \\ \& Valdenir Veronese Furtado
}

Instituto Oceanográfico da Universidade de São Paulo

(Caixa Postal 66149, 05315-970 São Paulo, SP, Brasil)

- Abstract: A historical analysis of sedimentologic research of the coast of the State of São Paulo is presented. The analysis concentrates his focus on the second half of the $20^{\text {th }}$ century, where most of the investigation have been developed, but early reports and investigation are also considered dating back as far as the $17^{\text {th }}$ century. Nowadays the growth of research intituition as well as the adoption of modern research methodologies acts as the main factors to the multiplication and consolidation of the diferent research approaches and to an increase in the knowledge of the evolution of the different sedimentological environments.

- Resumo: Este trabalho consiste em uma análise crítica sobre o desenvolvimento das pesquisas voltadas à sedimentação atual em áreas submersas na região costeira do Estado de São Paulo. Esta análise baseou-se nos aspectos fundamentais que nortearam, ao longo do tempo, o avanço dessa linha do conhecimento, ou seja, fundamentos temáticos e metodológicos, inserindo-os dentro dos diferentes contextos e momentos históricos. $O$ estudo da sedimentação atual nessa região vem se desenvolvendo, de forma efetiva, a partir da segunda metade deste século. Tem, entretanto, sua origem, nos antigos estudos sobre a região litorânea, de caráter predominantemente descritivos. No decorrer do tempo, o reconhecimento das características fisiográficas alavancou, tanto o interesse acadêmico quanto pela potencialidade econômica mineral. Inevitavelmente, o desenvolvimento das instituições de pesquisa, atendo-se à necessidade de gerar e ampliar o conhecimento, levou os pesquisadores a consolidarem a pesquisa sobre os ambientes marinhos submersos. A orientação geral e os ramos particulares que estes estudos tomaram estão relacionados aos aspectos metodológicos, a partir do momento em que as linhas básicas da pesquisa se consolidaram. A possibilidade de utilização de diferentes metodologias permitiu que as pesquisas tivessem alternativas na obtenção de respostas sobre as causas naturais dos eventos que ocorrem na região costeira.

- Descriptors: Sedimentation, Coastal environments, State of São Paulo, Southeastern Brazilian coast.

- Descritores: Sedimentação atual, Ambientes costeiros submersos, Estado de São Paulo, Costa sudeste brasileira. 


\section{Introdução}

O litoral, faixa de contato entre o mar e o continente, possibilita vários tipos de estudo, pois é uma área essencialmente dinâmica, passível de modificações, tanto lentas como rápidas, no espaço e no tempo. Um destes tipos de estudo é a sedimentação litorânea (Cruz, 1961).

Ao longo do tempo, os estudos sobre este tema têm variado nos enfoques e na forma de abordagem, em função da própria evolução do conhecimento, assim como do desenvolvimento metodológico, da disponibilidade de equipamentos e laboratórios e do número crescente de pesquisadores envolvidos em projetos afins.

Desta forma, este trabalho tem, como objetivo, a realização de uma avaliação sobre pesquisas efetuadas visando reconstituir 0 desenvolvimento do conhecimento das características geológicas da região costeira do Estado de São Paulo enfocando, em especial, os trabalhos voltados à sedimentação atual em áreas submersas. Para isso foram também considerados trabalhos realizados no final do século XIX e nas primeiras décadas deste século, que se caracterizaram por expedições de reconhecimento, estudos de caráter geográfico e geomorfológico, além de pesquisas arqueológicas com implicações paleoambientais por terem gerado algumas questões que vieram motivar o estudo atual de ambiente sedimentares costeiros no litoral paulista.
Procurou-se, dessa forma, abordar esta evolução dando ênfase histórica aos aspectos temáticos e metodológicos, utilizados pelos pesquisadores que atuaram neste campo de trabalho, situando-os temporal e espacialmente. Este enfoque propiciou a obtenção de um panorama do conhecimento sobre as Geociências no litoral paulista, em especial a Sedimentologia, desde seus primórdios até os dias atuais, caracterizando-se, também, como um levantamento do estado da arte da sedimentação atual em áreas submersas no estado de São Paulo.

\section{Localização e características fisiográficas do litoral paulista}

Localizado na região sudeste da costa brasileira, o litoral do Estado de São Paulo apresenta uma linha de costa orientada preferencialmente para NNE-SSW (Fig. 1). Esta área compõe parte da Província Fisiográfica Litoral (Ab'Saber \& Bernardes, 1958), redefinida como Província Costeira, por Almeida (1964), como sendo a área do Estado drenada diretamente para o oceano, e constituíndo o rebordo do Planalto Atlântico. Segundo IPT (1981), a Província Costeira encontrase dividida, na região de estudo, em Subzona Serra do Mar (zona Serrania Costeira) e Zona das. Baixadas Litorâneas.

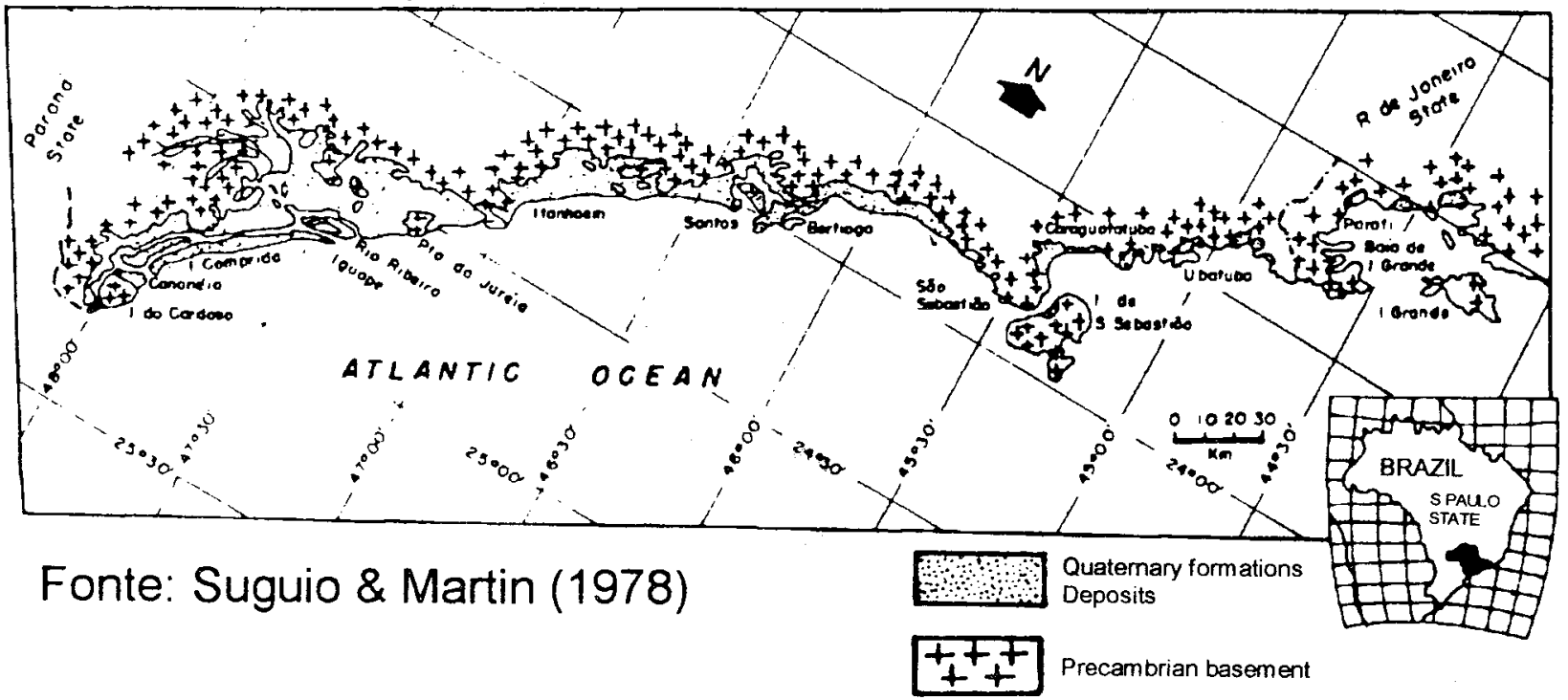

Fig. 1. Localização da área de estudo. 
O primeiro domínio é representado por relevos do tipo escarpas abruptas e festonadas, exibindo espigões que avançam para as baixadas, e escarpas com espigões digitados, compondo as terminações da Serra do Parati, onde alargam-se paralelamente às direções preferenciais NE das estruturas regionais. As escarpas festonadas apresentam declividades acima de $30 \%$, amplitudes maiores que 100 metros e drenagens com padrão subparalelo a dendrítico de alta densidade com comportamento bidirecional, e orientação preferencial para SE e NW.

A subzona Baixadas Litorâneas compõe-se de terrenos baixos e próximos ao nível do mar atual, com baixa densidade de drenagem. O sistema de relevo presente é composto por planícies costeiras. Estas desenvolvem-se sobre um pacote de sedimentos quaternários que obedecem, basicamente, ao mesmo padrão de distribuição em toda a costa paulista, variando apenas na espessura.

Considerando aspectos geológicos e um forte controle tectônico e estrutural, Fúlfaro et al. (1974) dividem, geomorficamente, as planícies costeiras paulistas em compartimentos, sendo os mais extensos localizados ao sul da região de Santos Bertioga. Segundo os mesmos autores este limite separa, ainda, a costa paulista em uma área com características de emersão mais pronunciada a norte e menos a sul, caracterizando um processo de emersão diferencial. Ao norte deste limite ocorre apenas um compartimento, o de Caraguatatuba, enquanto que a região sul divide-se nos compartimentos Santos-Itanhaém-Peruíbe e IguapeCananéia.

Por outro lado, Suguio \& Martin (19.78) dividem o litoral paulista em duas áreas. Ao norte, onde o embasamento pré-Cambriano atinge o mar em quase toda sua extensão, excetuando-se pequenas planícies, e ao sul, onde desenvolvemse grandes planícies separadas, entre si, por pontões do embasamento cristalino. Estas áreas são subdivididas em quatro unidades definidas, de sul para norte, como Unidade Cananéia - Iguape, Unidade Itanhaém - Santos, Unidade Bertioga - Ilha de São Sebastião, e Unidade Ilha de São Sebastião Serra do Parati.

Quanto às diferenças morfológicas entre o litoral sul e norte, os autores admitem a atuação de influências tectônicas. Os mecanismos responsáveis por esta distinção são atribuídos, segundo Fúlfaro $e t$ al. (op. cit.) a elementos tectônicos oblíquos à linha de costa, enquanto que Suguio \& Martin (op. cit.) apontam mecanismos de flexura continental diferencial, a partir de elementos tectônicos paralelos à linha de costa. Martin et al. (1985) analisando outras variações no processo eustático, associam esta diferenciação à posição relativa da Serra do Mar e a mudanças no campo geoidal.

Mahiques et al. (1990) propõem uma caracterização da costa paulista baseando-se em aspectos oceanográficos-geológicos-geomorfológicos, sem levar em consideração aspectos genéticos para esta classificação. A proposta visa uma caracterização mais precisa dos diversos segmentos da costa paulista, composta de grande diversidade de sub-ambientes, com objetivos de utilização em estudos sobre os ecossistemas da região costeira. Esta classificação baseou-se nos seguintes parâmetros: superficie da bacia de drenagem, declividade da área submersa, orientação da linha de costa, natureza dos sedimentos da área submersa, natureza litológica da área emersa e 0 fenômeno oceanográfico predominante, caracterizando um total de 26 subdivisões na costa paulista.

\section{Objetivos}

Este trabalho tem, como objetivo, analisar criticamente os avanços do conhecimento sobre a sedimentação em áreas submersas no Estado de São Paulo, considerando-se aspectos conceituais, temáticos e metodológicos, que definiram, de forma geral, as principais linhas de pesquisa que se desenvolveram ao longo do tempo, baseando-se no levantamento de referências bibliográficas e na seleção dos trabalhos, analisando-os e inserindo-os nos diferentes contextos históricos que representam.

Dessa forma, este estudo visa orientar as pesquisas ao longo da região abordada e facilitar a compreensão das informações levantadas, procurando servir como guia para definição de alvos de estudo, assim como servir de subsídio básico para levantamentos bibliográficos, nas áreas de estudo afins.

\section{Breve revisão histórica dos trabalhos sobre a região costeira produzidos até os meados da década de $\mathbf{4 0}$}

As pesquisas no litoral paulista tiveram início no século passado, e o conhecimento sobre seu desenvolvimento até meados da década de $\mathbf{4 0}$ mostra claramente as limitações e dificuldades enfrentadas na realização dos trabalhos. Esta fase caracterizou-se, essencialmente, pelo estudo de áreas emersas, quando foram realizados mapeamentos gerais sobre a morfologia da paisagem, estudos sedimentológicos em praias e enfoques generalizados sobre a evolução do litoral. 
O presente trabalho, embora tenha como enfoque principal o estudo de áreas submersas, procura apresentar um panorama deste período, fornecendo subsídios para compreensão dos caminhos percorridos pela pesquisa até chegar aos estudos atuais.

Datam do início do século XVII os primeiros levantamentos cartográficos da costa paulista, com destaque para o litoral compreendido entre a Vila de São Vicente e o Rio de Janeiro (Taunay, 1922). Já a partir dos primeiros documentos cartográficos são estabelecidas as toponímias utilizadas até hoje nas cartas náuticas. Entretanto, data apenas de 1789 a "primeira tentativa scientifica de levantamento rigoroso de todo o littoral de São Paulo, desde os limites com Santa Catharina até a fronteira do Rio de Janeiro", através da publicação da "Carta corographica e hydrographica de toda a costa do mar da Capitania de São Paulo". em que constam, além de dados batimétricos da costa paulista, cartas de detalhe da Baía de Santos, parte sul da região de Cananéia, e enseadas de Guaratuba e Paranaguá (Taunay, op. cit.).

A partir do século XIX, o litoral paulista passou a ser estudado dentro do contexto das ciências naturais, sendo que a primeira referência identificada corresponde ao trabalho de Loefgren (1893), onde o autor estuda sambaquis encontrados no litoral paulista, alguns distantes até $20 \mathrm{~km}$ da linha de costa. Os registros desses sambaquis forneceram, posteriormente, subsídios para análises sobre variações do nível médio do mar.

A partir deste marco, até a primeira década deste século, as pesquisas desenvolvidas na região resumem-se a um grande levantamento sobre as características naturais da Ilha de São Sebastião, com ênfase nos aspectos biológicos, geológicos, oceanográficos e geográficos (Ihering, 1897), às informações acerca das situações dos sambaquis de Itanhaém e Santos, descritas em Calisto (1905), à exploração do Rio Ribeira de Iguape (Comissão Geográfica e Geológica (1908, apud Ab'Saber, 1955) bem como às descrições sobre a paisagem, fauna $e$ flora da região de São Sebastião, feitas por Goursand (1910), dentro de uma expedição realizada ao litoral norte de São Paulo.

Com uma nova postura investigativa, os levantamentos descritivos subseqüentes tiveram, como princípio, um reconhecimento de caráter mais regional, sendo desta época os trabalhos de Krone (1914, apud Ab'Saber, 1955), delimitando o traçado antigo do golfão de Cananéia, e os trabalhos fundamentais da Comissão Geográfica e Geológica (1915, 1919, 1920, apud Ab'Saber, op cit.), o primeiro cobrindo da cidade de Santos à fronteira do Estado do Rio de Janeiro, o segundo realizando um reconhecimento do rio Juqueriquerê, retomando a linha do trabalho de 1908 e, finalmente, o último, cobrindo de Santos à fronteira com o Paraná, efetuando dessa forma, a caracterização dos grandes traços da fisionomia do litoral paulista sendo o primeiro levantamento vultoso, com caráter científico, na região.

Nesse mesmo período, Backheuser (1918, apud Cruz, 1974) tece considerações acerca dos aspectos geológicos-geomorfológicos da Serra do Mar no litoral norte paulista e dos movimentos regressivos marinhos, caracterizando a região como submetida a um processo de emersão não completada, considerando o canal de São Sebastião como originário de uma falha submarina e os sambaquis estudados por Loefgren (1893) como indicadores de paleoníveis marinhos. Com isto, o autor apresenta o primeiro trabalho de cunho efetivamente integrado, com interpretações tanto geomorfológicas e geológicas como arqueológicas, obtendo informações que permitiram postular sobre os processos evolutivos da área.

Os estudos sobre as características fisiográficas do litoral paulista são retomados apenas a partir da década de 30, com o trabalho de Moraes Rêgo (1932), que se refere a movimentos epirogenéticos na fixação da linha de costa.

Os trabalhos posteriores retomam os levantamentos de caráter regional, como Deffontaines (1935), descrevendo regiões e paisagens do Estado de São Paulo, e Fiore (1939), com a documentação de sambaquis, ambos compreendendo, como área de estudo, todo o Estado de São Paulo.

Knecht (1939) publica o primeiro trabalho na área da sedimentologia com enfoque petrográfico e econômico, caracterizando, composicionalmente, sedimentos praiais, visando a determinação de ocorrências de minérios de ferro e pirita em São Paulo. Com este trabalho, iniciam-se as pesquisas específicas em sedimentologia no litoral paulista.

Durante a década de 40 , a temática predominante nos trabalhos sedimentológicos realizados seguiu a linha apresentada por Knecht (op. cit.). Estes trabalhos, porém, visavam identificar, ao longo das praias do litoral paulista, ocorrências de minerais de interesse econômico, realizando estudos da composição mineralógica e dos teores em elementos químicos, preferencialmente metálicos, nas amostras coletadas.

Destaca-se, neste período, a caracterização composicional de areias ilmeníticas na praia da Juréia e outras ocorrências semelhantes no litoral paulista (Knecht, 1944); e a análise realizada nas areias de São Vicente, disponibilizando sua utilização para o fabrico de vidro (Carvalho, 1945). 
Esta linha de pesquisa abordando sedimentos praiais, voltada tanto ao reconhecimento da potencialidade econômica das areias do litoral paulista como ao reconhecimento e identificação de diferentes ambientes de sedimentação, desenvolvemse até o início dos anos 60, destacando, neste contexto, os trabalhos de Freitas (1951 a, b, c, d) e Freitas (1953). O autor realiza uma série de levantamentos sobre as características granulométricas e composicionais das areias recentes de praias em várias localidades do litoral paulista. Destacam-se, também, os trabalhos de Freitas (1960 $\mathrm{a}, \mathrm{b})$, analisando a mineralogia e a geologia das areias de praia de Caraguatatuba a Ubatuba e entre São Sebastião e Caraguatatuba, respectivamente.

Este tipo de estudo foi sendo gradualmente abandonado, em função de resultados insatisfatórios do ponto de vista da exploração mineral das areias do litoral paulista.

A partir do ano de 1946, com a fundação do "Instituto Paulista de Oceanografia", têm início uma nova abordagem para os estudos na região costeira, embasados pela visão e perspectivas científicas do Prof. Wladimir Besnard, desenvolvendo e consolidando, através de seus seguidores, uma linha de pesquisa voltada ao conhecimento geológicooceanográfico.

\section{Análise crítica da evolução do conhecimento sobre a sedimentação atual em ambientes costeiros submersos do estado de São Paulo, a partir de 1950}

A partir de Besnard (1950), uma nova concepção nos estudos na faixa litorânea tem início, visto que o autor elabora um ensaio hipotético sobre a gênese da região lagunar de Cananéia-Iguape até um estágio atual, sob o ponto de vista das relações entre a evolução morfológica da região e a dinâmica marinha. Evidencia a continuidade e a velocidade das transformações no ambiente, inclusive a influência antrópica associada à abertura do canal do Valo Grande, em 1830 (Krug, 1939, apud Besnard, op. cit.), identificando os processos de transporte e sedimentação na área a partir deste evento e, finalmente, fazendo conjecturas a respeito da morfologia da região em um tempo futuro (Fig. 2): Assim, este pode ser considerado como o primeiro trabalho de cunho oceanográfico-geológico no Estado de São Paulo, passando este tema a ser o enfoque desta revisão, e fonte para as análises sobre o seu desenvolvimento.
Dentro deste contexto, que abrange as pesquisas em áreas submersas voltadas à sedimentação atual destacam-se, seqüencialmente, os trabalhos desenvolvidos por Sadowsky (1952, 1953, 1954), onde o autor realiza o acompanhamento e a análise das variações na morfologia da desembocadura lagunar de Cananéia ao longo de dois anos consecutivos, visando a detecção dos fenômenos de ataque às margens do canal de entrada do sistema, as modificações da linha de costa da região e, também, os deslocamentos e acúmulo de sedimentos ao longo da área (Figs 3a, 3b).

$O$ autor, dessa forma, seguindo os pressupostos de Besnard (1950), realiza o primeiro trabalho de controle da intensidade e dos efeitos resultantes da atuação dos processos sedimentares na região costeira de São Paulo.

Os principais trabalhos subseqüentes apresentam uma grande evolução temática $\mathrm{e}$ metodológica nas pesquisas em áreas submersas, passando a utilizar-se de amostradores na coleta de sedimentos de fundo, e submetendo-os a análises granulométricas, de teor de carbonato biodetrítico e do conteúdo e das características da matéria orgânica. Tais trabalhos tiveram, como objetivo, o reconhecimento dos vários agentes dinâmicos atuantes na deposição e o padrão geral de circulação marinha em ambientes costeiros, através da caracterização dos sedimentos superficiais.

Estes estudos, relativos à dinâmica sedimentar foram desenvolvidos e aplicados inicialmente por Kutner $(1962,1963)$, e Magliocca \& Kutner (1965) criando uma linha de pesquisa que predomina em publicações sobre sedimentação até a metade da década. Estes trabalhos representam um importante avanço nas pesquisas, quando comparados aos de Sadowsky (1952, 1953, 1954), voltados à análise da dinâmica costeira, pois apresentam um enfoque voltado à caracterização sedimentológica e à determinação das causas que geram a tipologia e as feições sedimentares de fundo (Fig. 4).

Esta linha têm um grande desenvolvimento a partir da segunda metade da década de 1960 , quando da expansão das atividades portuárias e das obras de engenharia na costa paulista.

Nesse período, os principais trabalhos começaram a apresentar-se vinculados a projetos associados a órgãos públicos e empresas privadas, tais como o trabalho do EPUSP/DAEE (1966), sobre assoreamento na área portuária de Santos, e o trabalho de Kutner (1969, apud Kutner,1976), para a firma Brasconsult, destinado ao projeto do Porto de São Sebastião, ambos realizados seguindo as propostas metodológicas aplicadas a partir de Kutner (1962). 

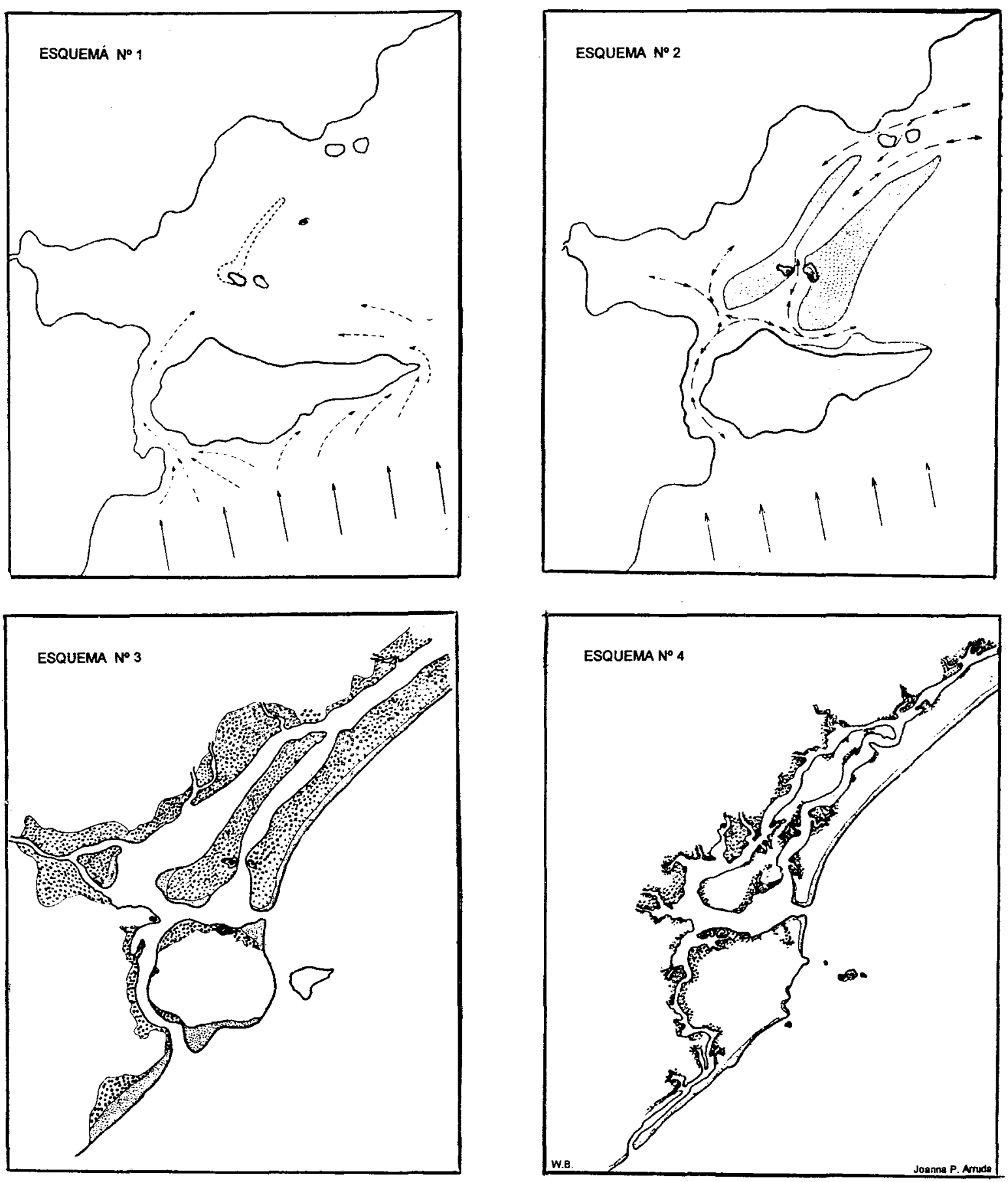

Fig. 2. Esquema evolutivo da desembocadura do sistema estuarino lagunar de Cananéia.

Destaca-se, também, a publicação do extenso relatório sobre o Complexo Valo Grande, Mar Pequeno e rio Ribeira de Iguape, pela GEOBRÁS (1966), que apresenta uma visão integrada de aspectos geomorfológicos regionais com as características atuais e pretéritas do sistema costeiro e o papel da drenagem continental na estabilidade e evolução desses ecossistemas.
A década de 70 caracteriza-se por um aumento considerável na quantidade de trabalhos voltados à sedimentação de forma geral, isso em função do envolvimento de uma maior diversidade de pesquisadores, aplicando e desenvolvendo novas metodologias, com objetivos variados, envolvendo, tanto ciência aplicada como de interesse acadêmico, em várias escalas espaciais. 

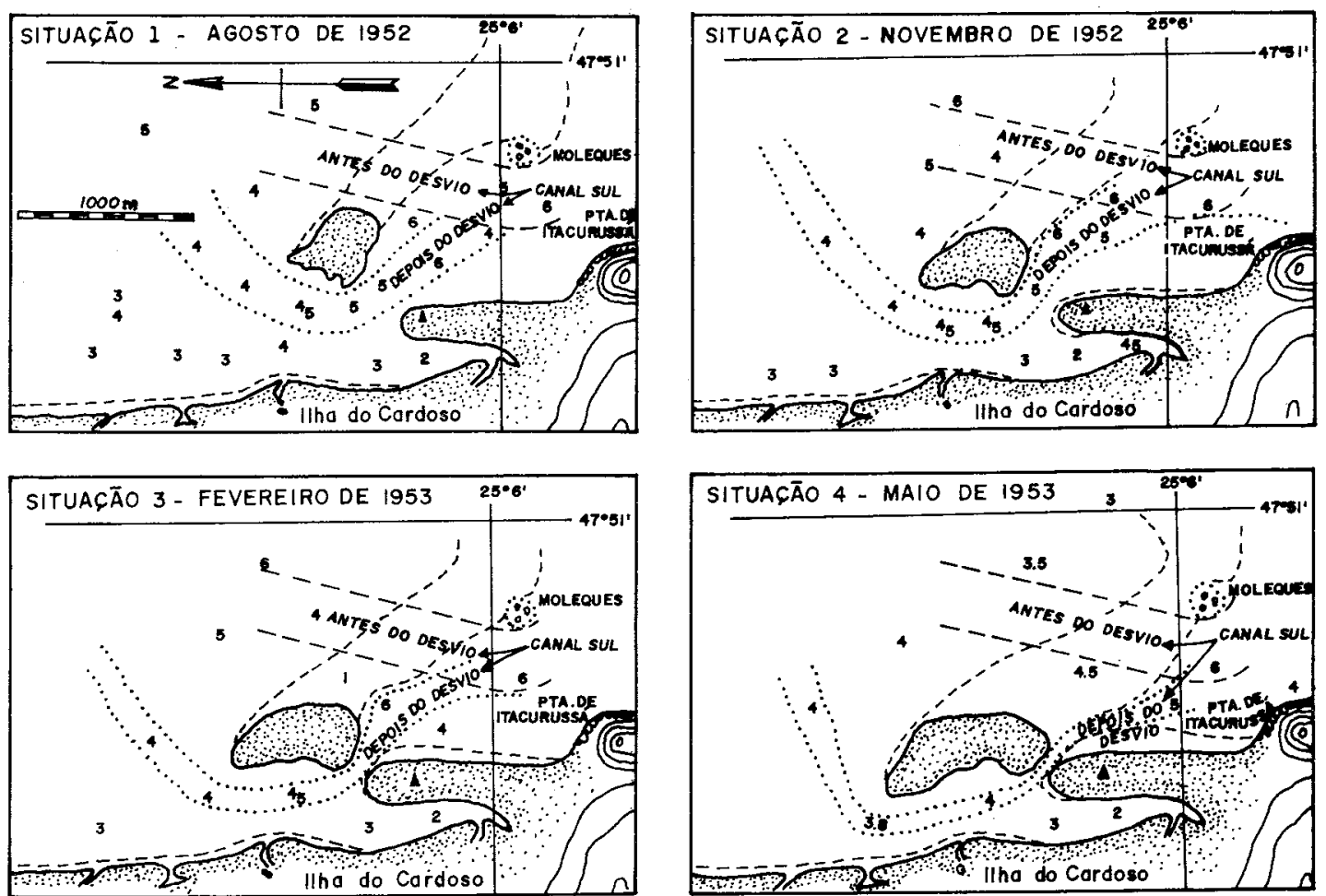

Situaçāo 1 - Aspecto da regiōo por ocasiōo do primeiro levantamento efetuado.

Situaçōes 2, 3 e 4 - Progressāo do 'llho Nova', crescimento do esporōo e estrangulamento do Canal Sul.
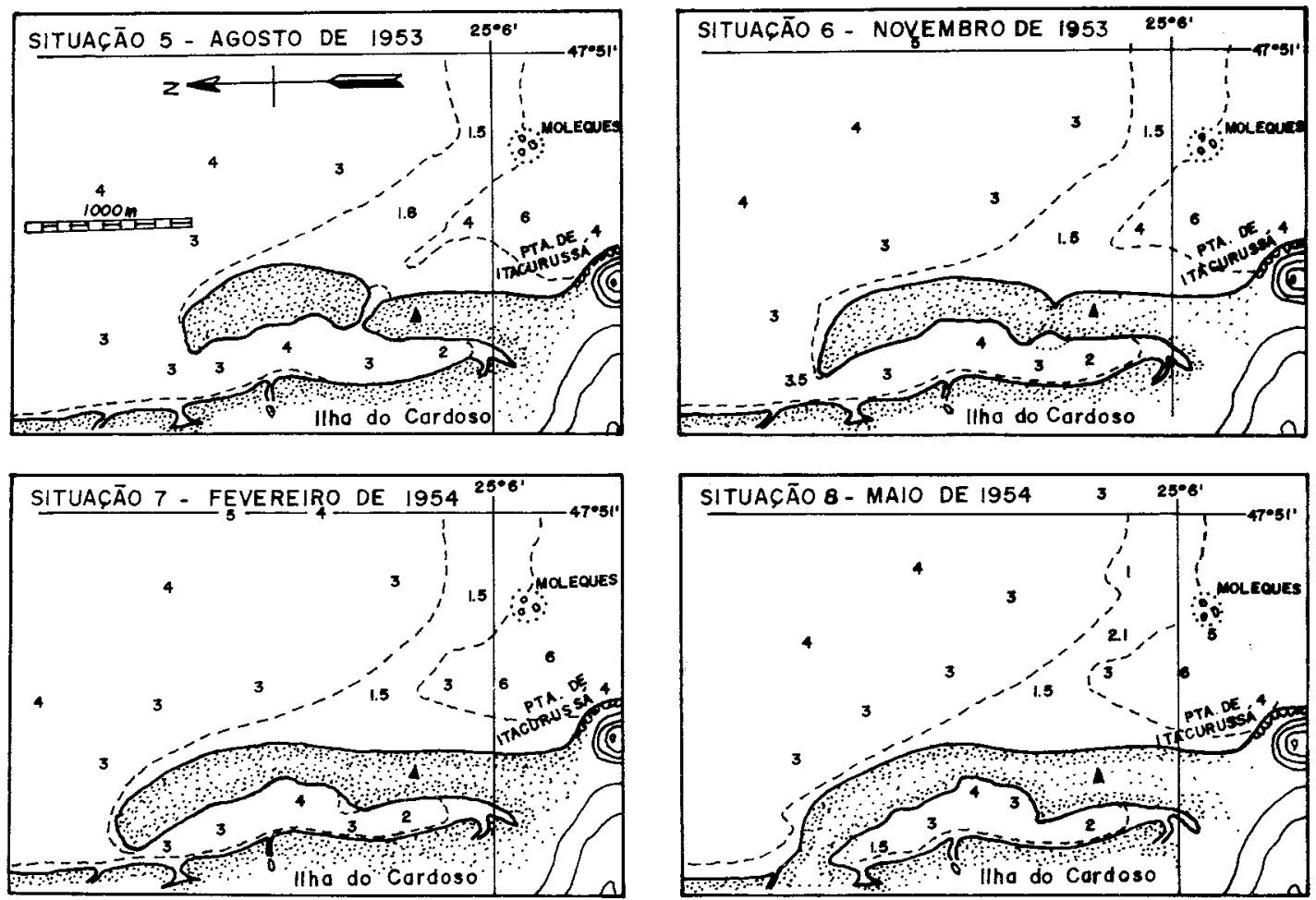

Situaçōes 5,6,7e8 - Formaçđo da restingo, fechamento da laguna e retilinizacão da costa.

Adaptado de Sadowsky (1954)

Fig. 3a. Gênese e evolução de uma laguna na llha do Cardoso. 


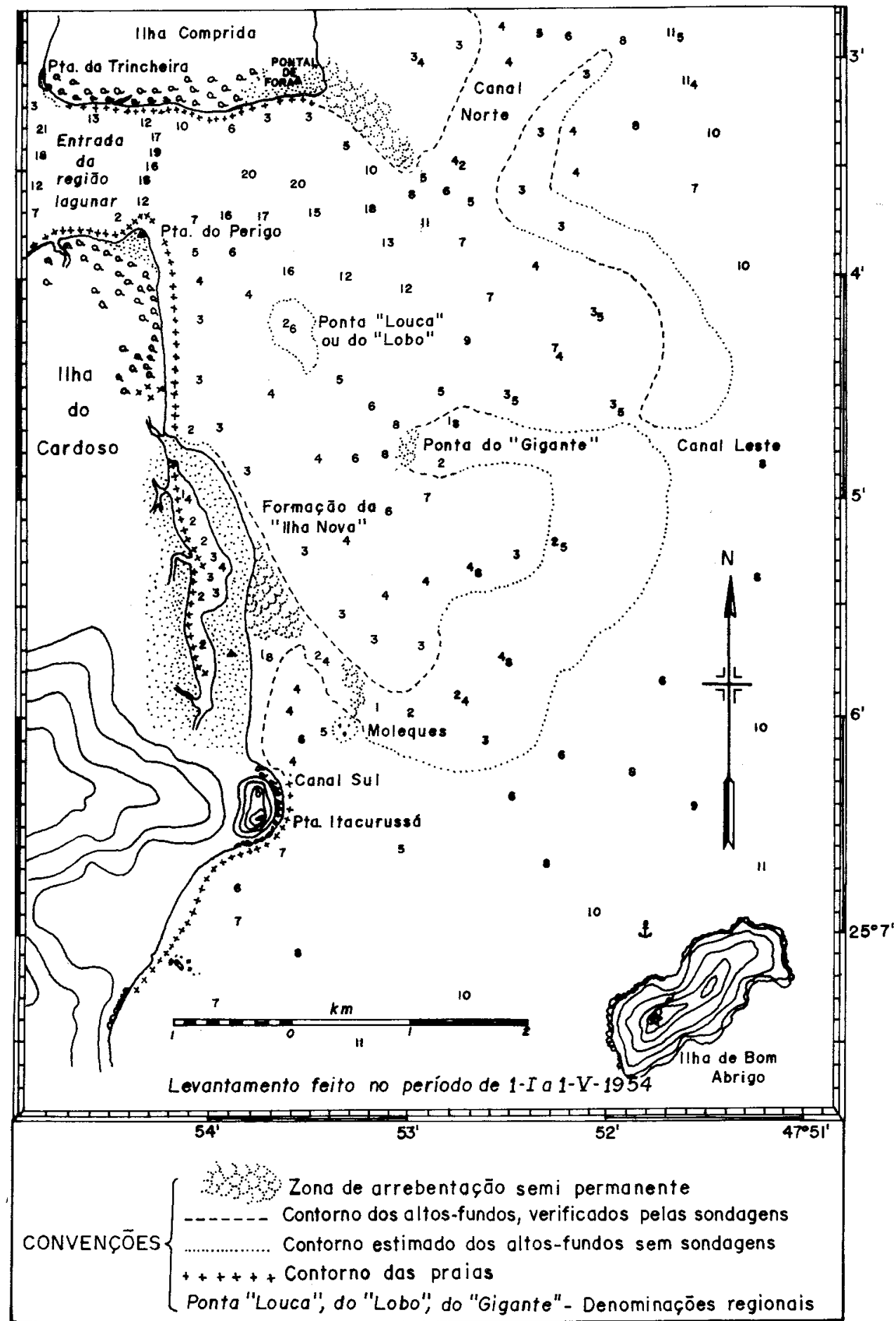

Adaptado de Sodowsky (1954)

Fig. 3b. Variações dos canais secundários da Barra de Cananéia. 


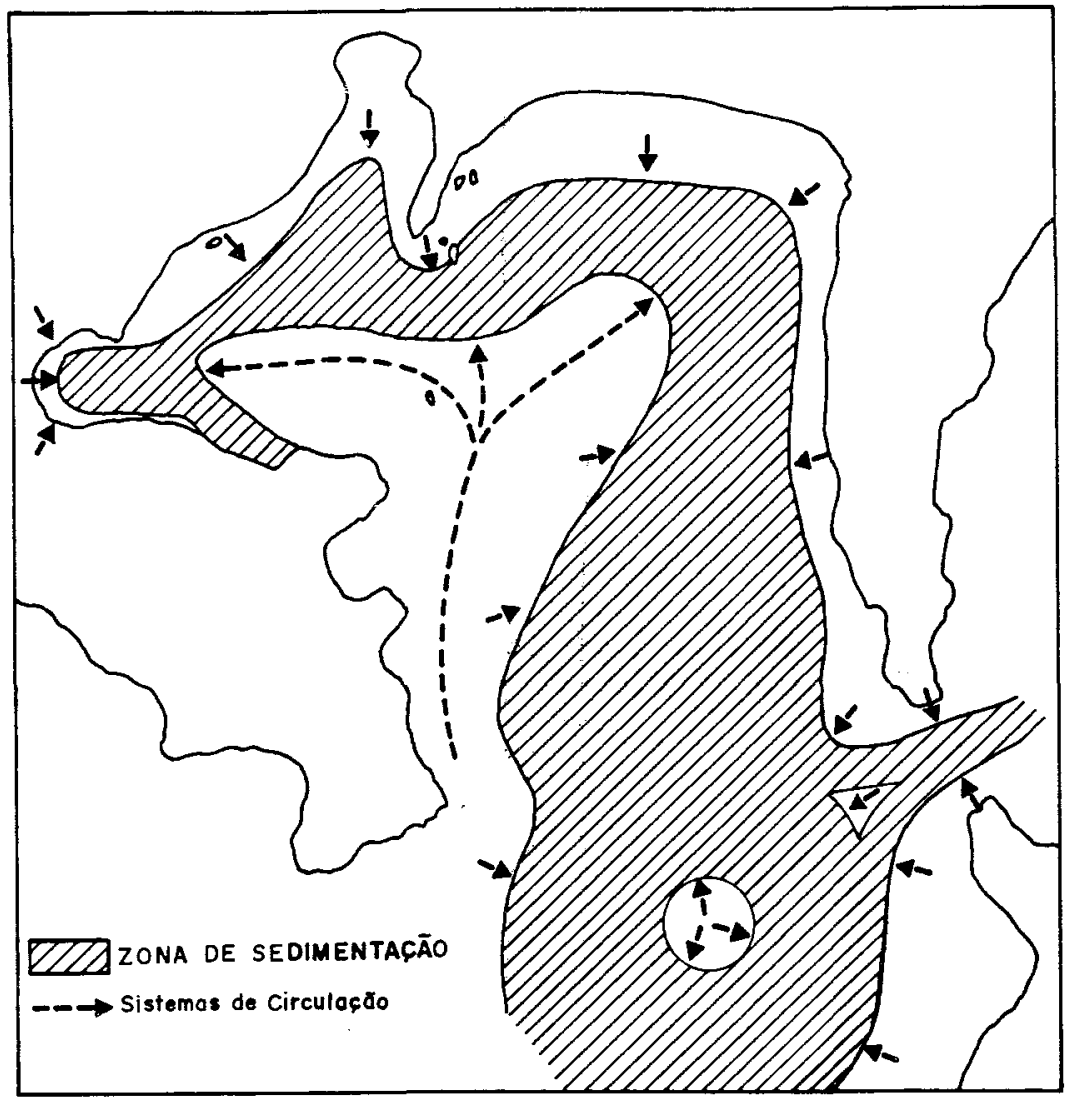

Adaptado de Magliocca \& Kutner (1965)

Fig. 4. Esquema geral do mecanismo do transporte e deposição dos sedimentos na enseada do Flamengo-Ubatuba.

O escopo dos trabalhos publicados voltou-se, predominantemente, a estudos das características da sedimentação de áreas emersas, baseados em observações de campo, análises granulométricas e composicionais dos sedimentos, observações sobre a dinâmica marinha incidente, caracterização de ambientes deposicionais e evidências de variações pretéritas do nível médio do mar além de estudos de correlação estratigráfica. Foram levantamentos de âmbito tanto regional como restrito à praias de grande extensão do litoral sul de São Paulo, e a pequenos embaimentos da porção norte do Estado.

Apesar de trabalhos anteriores já abordarem a evolução quaternária do litoral paulista, tais como Bigarella (1965), Bigarella et al. (1965) e Ab'Saber (1965) destacam-se, nesse contexto, os trabalhos de Petri \& Suguio (1973) e Suguio \& Petri (1973), que analisaram a evolução sedimentar em áreas emersas, descrevendo as características da costa de sedimentação instável na região da desembocadura lagunar de Cananéia. Reconhecem, na área, cinco unidades geomorfológicas, e tecem considerações a respeito das porções submersas adjacentes, além de observarem as relações entre padrões de correntes associadas a marés e o transporte de sedimentos. Os autores estudaram também a estratigrafia do quaternário da área, sendo deles a primeira menção à Formação Cananéia associada a eventos transgressivos pleistocênicos.

Fúlfaro et al. (1974) dentro da linha de flutuações relativas do nível médio do mar, analisaram a gênese e evolução das planícies costeiras do litoral paulista. Suguio \& Martin (1976 a, b) desenvolveram metodologia para estudo sobre a gênese e evolução dessas planícies, que culminaram com a publicação de um trabalho sobre formações Quaternárias marinhas no Estado de São Paulo (Suguio \& Martin, 1978). A partir deste último ocorre um grande desenvolvimento dos trabalhos em áreas emersas, voltados ao reconhecimento e à compreensão dos processos sedimentares que caracterizaram a evolução do litoral paulista durante o Quaternário.

Estes trabalhos consistiram de observações de campo, análises de testemunhos de sondagem, datações e correlações com dados bibliográficos anteriores que, ao longo da década de 1980, consistiram na mais proficua linha de pesquisa voltada ao conhecimento das regiões litorâneas do Estado de São Paulo, fornecendo bases metodológicas 
e conceituais para este tipo de estudo nas diferentes áreas da costa brasileira.

Como resultado, foi obtida, não apenas toda a caracterização dos sedimentos da planície costeira e sua correlação com a estratigrafia do Quaternário do Estado, como também a definição desta última, evidenciando os processos de variações relativas do nível médio do mar através dos registros sedimentares preservados nas áreas emersas e de testemunhos de sondagem. Destaca-se, neste período, de forma fundamental, os trabalhos publicados pelos pesquisadores Kenitiro Suguio (Instituto de Geociências - USP) e Louis Martin (ORSTOM).

Paralelamente aos estudos mencionados ocorre, no ano de 1976, uma retomada, em uma série de trabalhos, do enfoque voltado para o interesse de áreas portuárias, de manutenção ou implantação de portos, em especial no estuário e baía de Santos. Tiveram caráter predominantemente sedimentológico, utilizando-se da amostragem 'de sedimentos para a análise, interpretação e definição de fácies sedimentares, e da direção de transporte.

Esses levantamentos visavam a caracterização dos processos que atuam na modelagem da área, através dos parâmetros granulométricos dos sedimentos de fundo, utilizando, excepcionalmente, outros métodos tais como análise de imagens de satélite e acompanhamento do transporte do material em suspensão ao longo do sistema. De qualquer forma, a base metodológica desses trabalhos consiste em uma retomada dos conceitos aplicados por Kutner no início da década de 60. Dentre estes, destaca-se o trabalho de Kutner (1976), onde é sugerida uma metodologia de estudos para áreas costeiras submersas, associando as distribuições sedimentares ao comportamento hidrodinâmico.

Os trabalhos de Ponçano \& Fúlfaro (1976), Fúlfaro et al. (1976) e Fúlfaro \& Ponçano (1976), bem como a publicação do relatório final sobre o comportamento hidráulico e sedimentológico do estuário santista (IPH, 1977) e os trabalhos de Correia \& Ponzi (1978, 1979) definem as características sedimentares do canal e baía de Santos, permitindo a diferenciação da área em dois setores, um influenciado pelo canal do porto, a leste e outro influenciado por mar aberto, a oeste. Permitiram, também estabelecer a circulação geral da área.

No litoral norte do Estado, Furtado (1978) caracteriza os processos dinâmicos da sedimentação atual do Canal de São Sebastião, analisando cartas batimétricas, perfis de ecossondagens e análises granulométricas e composicionais de sedimentos, além de parâmetros oceanográficos físicos, tais como atuação de marés, padrão de ondas incidentes na boca sul do canal e comportamento de correntes, demonstrando uma maior preocupação com a utilização de parâmetros oceanográficos para a interpretação da dinâmica atuante em áreas costeiras e seus efeitos. Obteve, dessa forma, uma distribuição sedimentar associada a áreas de circulação mais intensas e menos intensas no canal, bem como as direções preferenciais do transporte de sedimentos na área.

Nota-se que as pesquisas realizadas em áreas submersas ao longo da década de 70 não apresentaram muitas inovações metodológicas, com relação às anteriores, porém, é fato o avanço no conhecimento da sedimentação atual em toda a costa paulista. Dentre esses trabalhos destacam-se o levantamento da distribuição de matéria orgânica nos sedimentos marinhos costeiros de Cananéia até Ubatuba realizado por Navarra et al. (1980), e os estudos de Tessler (1982) e Suguio \& Tessler (1983) que caracterizam a sedimentação em função da atuação da dinâmica marinha dentro do sistema Cananéia-Iguape, e na desembocadura do mesmo sistema, identificando as tendências de deposição e erosão no local.

Tessler \& Furtado (1984) avaliam, com base em fotografias aéreas de diferentes épocas, o comportamento de feições sedimentares nos canais lagunares da região de Cananéia-Iguape. $O$ trabalho procura evidenciar o crescimento dessas feições associado à dinâmica local das correntes de maré, procurando estabelecer a evolução e sentido de crescimento das mesmas.

A continuidade das pesquisas desenvolvidas seqüencialmente, segue as orientações básicas propostas nos trabalhos realizados ao longo das décadas anteriores, porém a possibilidade de aplicação de diferentes metodologias, em função do desenvolvimento técnico dos métodos de obtenção de dados, levou a uma diversificação nas formas de abordagem dos estudos de sedimentação no decorrer do tempo.

Neste sentido, Ponçano (1985) faz uma análise crítica sobre sedimentação atual aplicada a portos do Brasil, na qual integra informações de trabalhos anteriores, realizando uma síntese sobre o conhecimento e a aplicação dos estudos em obras portuárias, a partir das propostas metodológicas de Kutner (1962, 1963). Suguio et al. (1987), realizando perfilagens geofisicas associadas a levantamentos sobre a sedimentação, na região de Cananéia e Tessler et al. (1987) analisando os teores de elementos metálicos traços nos sedimentos de fundo na mesma área, apresentam novas aplicações metodológicas, criando perspectivas de novas formas de abordagem nas pesquisas realizadas no Estado de São Paulo. 
Neste período, destacam-se ainda trabalhos como o de Tessler (1988), que caracteriza o transporte de sedimentos ao longo do litoral sul paulista associando-o às relações entre os mecanismos de circulação atmosférica do continente sul americano e aos padrões de ondas incidentes sobre a costa, identificando-os como a base para a compreensão do deslocamento das correntes de fundo.

Os trabalhos realizados na década de 90 apresentam variações na postura científica, tanto analítica como metodológica, caracterizando-se pela continuidade na aplicação das diferentes linhas de pesquisa dos autores, e por novas propostas de diferentes pesquisadores, procurando, porém, em ambos os casos, compreender a resposta sedimentar como resultado de diversos fatores integrados que condicionam o meio.

Neste contexto, Souza (1990) estuda o comportamento sedimentar da região de Caraguatatuba, analisando os processos que ocorrem na planície costeira, na linha de costa e na enseada. Destacam-se, ainda, o levantamento oceanográfico e sedimentológico nas enseadas da região ao sul de Ubatuba, realizado por Mahiques $(1992)^{*}$, e o trabalho de Almeida et al. (1993), que correlaciona imagens TM-Landsat a parâmetros oceanográficos, material em suspensão e feições submersas. Bonetti Filho (1995), caracteriza as variações na configuração da desembocadura lagunar de Cananéia e o transporte de maierial em suspensão na porção sul do sistema, correlacionando informações oceanográficas com séries temporais de imagens de satélites.

Ao realizar um trabalho integrando metodologias utilizadas em outros campos da oceanografia, tais como, estações fixas de correntometria e termossalinidade e perfis termossalinométricos, além da coleta de amostras de sedimentos superficiais, analisadas quanto à granulometria e teores de carbono e nitrogênio orgânico e carbonato biodetrítico, Mahiques (1995) propõe o estabelecimento de um modelo de sedimentação para as enseadas ao sul de Ubatuba (SP), estabelecendo a correlação entre a circulação de fundo em sentido horário e a deposição de sedimentos siltosos e arenosos finos. $\mathrm{O}$ autor identifica, ainda, os principais mecanismos de aporte e remobilização de sedimentos, e definindo três níveis de variabilidade temporal: circa-anual, infraanual e geológico.

(*) Mahiques, M. M. 1992. Transporte de sedimentos na região costeira de Ubatuba, São Paulo. In: CONGRESSO BRASILEIRO DE GEOLOGIA, 37. Resumos. São Paulo, SBG. p. 187.
Avançando na abordagem realizada em Furtado (1978), ao associar perfis geofísicos e de batimetria de detalhe com dados sedimentológicos sobre o Canal de São Sebastião, Furtado (1995) analisou a distribuição dos sedimentos ao longo da área, tecendo considerações sobre o comportamento da dinâmica sedimentar atual e procurando identificar paleo superficies de deposição, indicativas de variações no comportamento dinâmico e, conseqüentemente, evolutivo da área, que possam ser condicionantes da sedimentação atual.

Souza (1995), utilizando-se de perfis contínuos com sonar de varredura lateral, identifica marcas onduladas na superficie de fundo dos canais da região de Cananéia, correlacionando-as com os processos hidrodinâmicos atuantes na área, tais como direções preferenciais de correntes, ponto de inversão de correntes de maré, e a conseqüente remobilização e transporte dos sedimentos.

Ampliando o conhecimento sobre o litoral norte do Estado de São Paulo, Rodrigues (1996), estudando as enseadas de Ubatumirim e Picinguaba, correlaciona as características e a distribuição dos sedimentos de fundo com dados de sonografia de varredura lateral, hidrodinâmica e meteorologia, demonstrando a grande heterogeneidade, tanto no comportamento da dinâmica atuante no meio quanto na resposta sedimentar, em termos espaciais e em diversos graus de variabilidade temporal. Este trabalho evidencia a necessidade do uso de escalas precisas e medidas sistemáticas no estudo de áreas costeiras.

Partindo dessas premissas, o autor obteve, como resultado, um padrão de circulação preferencial de sentido ante horário nas enseadas, e células de circulação horárias, junto às desembocaduras dos rios. Os sedimentos de fundo são predominantemente compostos por areias muito finas a finas, com manchas de sedimentos mais grossos. Identificou, ainda, estruturas alongadas associadas à passagem de sistemas frontais pela região, caracterizando uma sedimentação que forma um mosaico variável, temporal e espacialmente, na distribuição dos sedimentos.

Bonetti Filho \& Furtado (1996) utilizandose de um Modelo Digital de Terreno (MDT) gerado em ambiente SIG, para o litoral sul de São Paulo, identificam feições submersas, às quais inferem tendências deposicionais e erosivas, associando-as a ambientes específicos de sedimentação, e discutindo sobre a potencialidade $\mathrm{e}$ as facilidades de manipulação que a técnica oferece. Oferecem, dessa forma, uma nova perspectiva metodológica com relação aos trabalhos de mesmo enfoque, efetuados nesta mesma região, ao longo de décadas passadas. 
A análise dos trabalhos publicados mostram que as pesquisas desenvolvidas ao longo das décadas de 1980 e 1990 apresentam um amadurecimento gradativo nas preocupações com as escalas temporais dos processos que regem a sedimentação atual, A evolução do conhecimento e o desenvolvimento metodológico levou os pesquisadores a analisarem os registros sedimentares, como resultado de vários processos atuando conjuntamente e em diferentes escalas de tempo.

É evidente, nestes últimos trabalhos, o avanço do conhecimento sobre a sedimentação atual em ambientes marinhos submersos, sob a ótica da integração de diferentes parâmetros para a definição de seus resultados.

Essa integração reflete uma postura holística em que uma ampla abordagem metodológica se faz necessária para a compreensão do meio, em seu constante processo de adaptação às variações das condições energéticas atuantes, tanto em intensidade, quanto em escala temporal e espacial. A abordagem permite, também, compreender como cada um desses fatores é responsável pela conformação atual desse meio.

\section{Considerações finais}

Conforme pôde-se observar, as primeiras diretrizes da pesquisa sobre a sedimentação atual foram definidas ao longo das décadas de $1950 \mathrm{e}$ 1960 , sendo que os trabalhos desenvolvidos nas décadas posteriores tiveram, como apoio à evolução da pesquisa e do conhecimento, a evolução de equipamentos para coleta e análise de dados.

Tal fato possibilitou a adoção de novas formas e métodos de abordagem complementares aos procedimentos clássicos. Estes foram definidos, primeiramente, nos estudos de Besnard (1951) e Sadowsky $(1952,1953,1954)$ e, essencialmente, nos trabalhos realizados por Kutner ao longo da década de 60 , cujas propostas metodológicas permanecem atuais, caracterizando-se como princípios básicos neste campo de pesquisa.

Baseando-se porém, nestes conhecimentos, as pesquisas desenvolvidas ao longo das duas últimas décadas evoluíram para uma nova tendência, dentro da temática da sedimentação atual. Esta postura implicava na caracterização das influências da variabilidade temporal dos processos atuantes, em áreas costeiras, e os efeitos decorrentes da sua ação na configuração da superfície de fundo.

$$
\text { Esta ótica foi favorecida pelo }
$$

desenvolvimento, aprimoramento e pela disponibilidade de equipamentos e métodos analíticos. Dentre esses destacam-se a aplicação de métodos geofísicos, testemunhagens rasas, medições correntométricas e termossalinométricas, análises da composição da matéria orgânica dos sedimentos de fundo, técnicas de datação, aplicação de sistemas de informação geográfica, sensoriamento remoto, além da preocupação na identificação dos fenômenos de circulação atmosférica do Atlântico Sul e suas relações com os processos que regem a dinâmica e o balanço sedimentar ao longo da costa do Estado de São Paulo.

As condições atuais em que se desenvolvem as pesquisas permitem, não só o conhecimento, em detalhes, dos inúmeros processos dinâmicos que interferem sobre as áreas submersas da região costeira, como a identificação de suas responsabilidades na resposta sedimentar, sendo um grande avanço com relação à postura adotada nos trabalhos das décadas passadas. Estes previam a identificação da resposta sedimentar e, com base nessas informações, inferiam quanto aos processos dinâmicos a que a área foi submetida. Essas análises acabavam ficando restritas a informações de um determinado momento da evolução de uma área, não se atendo, como nos trabalhos mais recentes, aos conceitos de variação temporal, que prevê mudanças constantes nas características do meio em diferentes escalas de tempo.

O estudo sobre a dinâmica sedimentar na região costeira, que se caracteriza estruturalmente como uma delicada interface entre $o$ ambiente terrestre e marinho, mostra-se cada vez mais importante, não apenas como um interesse científico de caráter geológico-oceanográfico, mas também como fonte fundamental de subsídios à outras áreas das ciências do mar.

As perspectivas da evolução das pesquisas em sedimentação atual, nas porções submersas da região costeira se atém, além das possibilidades de levantamentos em áreas não estudadas, no aprofundamento do conhecimento já adquirido em áreas já estudadas, através das diferentes formas de abordagem exemplificadas nos trabalhos mais recentes.

A situação atual do desenvolvimento da pesquisa, incluindo aí a adoção de novas ferramentas e técnicas, como o sensoriamento remoto, o geoprocessamento e a modelagem numérica, tendem a impulsionar significativamente o conhecimento da dinâmica sedimentar e da evolução Quaternária nas áreas submersas de regiões costeiras, o que permitiria uma correlação com as informações levantadas nas porções emersas configurando, desta forma, todo o arcabouço geológico sedimentar do compartimento litorâneo do Estado de São Paulo durante o Quaternário. 


\section{Referências bibliográficas}

Ab'Saber, A. N. 1955. Contribuição à geomorfologia do litoral paulista. Revta bras. Geogr., 17(1):3-48.

Ab'Saber, A. N. 1965. A evolução geomorfológica. In: A Baixada Santista, aspectos geográficos: as bases fisicas. São Paulo, EDUSP, 1:49-66.

Ab'Saber, A. N. \& Bernardes, N. 1958. O Vale do Paraíba, Serra da Mantiqueira e arredores de São Paulo. In: CONGRESSO INTERNACIONAL DE GEOGRAFIA, 18. Rio de Janeiro, 1958. Guia de Excursões. Rio de Janeiro, CNG. 303p.

Almeida, F. F. M. de. 1964. Fundamentos geológicos do relevo paulista. Bol. Inst. Geogr. Geol., (41): 169-263.

Almeida, T. I. R.; Reinhardt, D.; Bontetti Filho, J.; Ferreira, S. A. \& Furtado, V. V. 1993. Aplicação de imagens TM - LANDSAT na detecção de água oceânica fria e sua correlação com sedimentos em suspensão e feições topográficas submersas. Bolm. IG, Inst. Geociências, Univ. S Paulo, 16:1-3.

Backheuser, E. 1918. A faixa litorânea: Brasil meridional hoje e ontem. Rio de Janeiro, Besnard Freres. 1v.

Besnard, W. 1950. Considerações gerais em torno da região lagunar de Cananéia-Iguape. II. Diversos aspectos atuais da região lagunar. Bolm Inst. paul. Oceanogr., 1(2):3-28.

Bigarella, J. J. 1965. Subsídios para o estudo das variações de nível oceânico no Quaternário brasileiro. An. Acad. bras. Ci., 37(2):263-278.

Bigarella, J. J.; Mousinho, M. R. \& Silva, J. X. 1965. Process and environments of the brasilian quaternary. In: SYMPOSIUM ON COLD CLIMATES PROCESS AND ENVIRONMENT, FAIRBANKS. Curitiba, 1965. Proceedings. Curitiba, UFPR. $71 \mathrm{p}$.

Bonetti Filho, J. 1995. Transporte de sedimentos por suspensão nas proximidades da Barra de Cananéia - São Paulo. Dissertação de mestrado. Universidade de São Paulo, Instituto Oceanográfico. $2 \mathrm{v}$.
Bonetti Filho, J. \& Furtado, V. V. 1996. Modelo numérico de terreno aplicado ao estudo de feições costeiras submersas no litoral sul do Estado de São Paulo. Geociências, S Paulo, 15(2):367-380.

Calisto, B. 1905. Algumas notas e informações sobre a situação dos sambaquis de Itanhaém e de Santos. Revta Mus. paul., 6:490-518.

Carvalho, J. G. 1945. Areia de São Vicente, Estado de São Paulo, para a fabricação de vidro. Bolm. Lab. Prod. Min., (16):91-1020.

Correia, I. C. S. \& Ponzi, V. R. A. 1978. Contribuição a sedimentologia do Canal e Baía de Santos (SP). In: CONGRESSO BRASILEIRO DE GEOLOGIA, 30. Recife, 1978. Anais. Recife, SBG. p. 851-866.

Correia, I. C. S. \& Ponzi, V. R. A. 1979. Contribuição à sedimentologia da Baía e Canal de Santos. Pesquisas, Porto Alegre, 10:11-30.

Cruz, O. 1961. Contribuition à l'étude géomorphologique de la région de GranvilleCarolles, La Manche, France. These de Diplôme de L'École Pratique des Hautes Études. Paris, Université de Paris. 108 p.

Cruz, O. 1974. A Serra do Mar e o litoral na área de Caraguatatuba - SP: contribuição à geomorfologia litorânea tropical. IG - série de teses e monografias, (11):9-181.

Deffontaines, P. 1935. Regiões e paisagens do Estado de São Paulo: primeiro esboço de divisão regional. Revta bras. Geogr., 1(2):117-169.

EPUSP/DAEE. Escola Politécnica da Universidade de São Paulo/Departamento de Águas e Energia Elétrica. 1966. O estuário santista: pesquisa sobre $o$ assoreamento verificado na faixa portuária, para a Companhia Docas de Santos. São Paulo, EPUSP. 6v.

Fiore, O. de. 1939. Sambaquis e egacaras no Estado de São Paulo. Vida portuguesa, S Paulo, 2(6):260-80.

Freitas, R. O. de. 1951a. Areias recentes da Praia Grande , S.P. An. Acad. bras. Ci., 23(2):163175. 
Freitas, R. O. de. 1951b. Areias recentes do Guarujá, S.P. An. Acad. bras. Ci., 23(2):177-186.

Freitas, R. O. de. 1951c. Composição e granulometria de Bertioga, São Paulo. São Paulo, José Magalhães. 12p.

Freitas, R. O. de. 1951d. Sobre a origem da Bacia de São Paulo. Bol. Paul. Geogr., 9:60-64.

Freitas, R. O. de. 1953. Composição e granulometria da praia de São Sebastião, São Paulo. Bolm Soc. Bras. Geol., 2(1):29-36.

Freitas, R. O. de. 1960a. Mineralogia e geologia de areias de praias de Caraguatatuba a Ubatuba. Publ. E. E. São Carlos, 30 (11):1-91.

Freitas, R. O. de. 1960b. Mineralogia e geologia de areias de praia entre São Sebastiãó e Caraguatatuba. Publ. E. E. São Carlos, 31(12):182.

Fúlfaro, V. J. \& Ponçano, W. L. 1976. Sedimentação atual do estuário e baía de Santos: um modelo geológico aplicado a projetos de expansão da zona portuária. In: CONGRESSO BRASILEIRO DE GEOLOGIA DE ENGENHARIA, 1. Rio de Janeiro, 1976. Anais. São Paulo, ABGE, 2:67-90.

Fúlfaro, V. J.; Suguio, K. \& Ponçano, W. L. 1974. A gênese das planícies costeiras paulistas. In: CONGRESSO BRASILEIRO DE GEOLOGIA, 28. Porto Alegre, 1974. Anais. Porto Alegre, SBG, 3:37-42.

Fúlfaro, V. J.; Ponçano, W. L. \& Gimenez, F. G. 1976. Sobre o significado dos depósitos argilosos do estuário santista: contribuição ao estabelecimento de um modelo de sedimentação da área de interesse ao porto. In: CONGRESSO BRASILEIRO DE GEOLOGIA DE ENGENHARIA, 1. Rio de Janeiro, 1976. Anais. São Paulo, ABGE, 2:141-149.

Furtado, V. V. 1978. Contribuição ao estudo da sedimentação atual no Canal de São Sebastião. Tese de doutorado. Universidade de São Paulo, Instituto de Geociências. 2v.

Furtado, V. V. 1995. Sedimentação quaternária no Canal de São Sebastião. Publção esp. Inst. oceanogr., S Paulo, (11):27-35.
GEOBRÁS - GEOBRÁS S/A Engenharia e Fundações. 1966. Complexo Valo Grande - Mar Pequeno - Rio Ribeira de Iguape. Relatório para o serviço do Vale do Ribeira. São Paulo, DAEE. $2 \mathrm{v}$.

Goursand, C. 1910. Uma viagem ao litoral norte de São Paulo. Rev. Inst. Hist. Geogr., S Paulo, 15.

Thering, H. von. 1897. A ilha de São Sebastião. Revta Mus. paul., 2:129-170.

IPH - Instituto de Pesquisas Hidroviárias. 1977. Comportamento hidráulico e sedimentológico do estuário santista: relatório final. São Paulo, Sondotécnica. $2 \mathrm{v}$.

IPT - Instituto de Pesquisas Tecnológicas do Estado de São Paulo. 1981. Mapa geológico do Estado de São Paulo, escala 1:500.000. São Paulo, IPT.

Knecht, T. 1939. As ocorrências de minérios de ferro e pirita no Estado de São Paulo. Bolm Inst. Geogr. Geol., (25): 7-127.

Knecht, T. 1944. Areias ilmeníticas na praia de Juréia, município de Iguape.OI.G.G. Revta Inst. Geogr. Geol., 2(4):334-336.

Kutner, A. S. 1962. Granulometria dos sedimentos de fundo da região de Cananéia, SP. Bolm Soc Bras. Geol., 11(2):41-54.

Kutner, A. S. 1963. Sedimentologia. Contrções Inst. oceanogr., Univ. S Paulo, ser. Oceanogr. fis., (5):25-40.

Kutner, A. S. $1976 . \quad$ Levantamentos sedimentológicos de apoio na pesquisa $e$ reconhecimento de áreas portuárias. In: CONGRESSO BRASILEIRO DE GEOLOGIA DE ENGENHARIA, 1. Rio de Janeiro, 1976. Anais. São Paulo, ABGE, 2:47-65.

Loefgren, A. 1893. Os sambaquis. Bolm. Com. Geogr. Geol., (9):1-91.

Magliocca, A. \& Kutner, A. S. 1965. Sedimentos de fundo da Enseada do Flamengo - Ubatuba. Contrções Inst. oceanogr. Univ. S Paulo, sér. Oceanogr. fís., (8):1-15.

Mahiques, M. M. 1995. Dinâmica sedimentar atual nas enseadas da região de Ubatuba, Estado de São Paulo. Bolm. Inst. oceanogr., S Paulo, 43(2):101110. 
Mahiques, M. M.; Suguio, K.; Tessler, M. G.; Furtado, V. V. \& Eicheler, B. B. 1990. Parâmetros oceanográfico - geológico geomorfológicos de interesse na caracterização de ecossistemas costeiros do Estado de São Paulo. In: SIMPÓSIO SOBRE ECOSSISTEMAS DA COSTA SUL E SUDESTE BRASILEIRA: ESTRUTURA, FUNÇÃO E MANEJO, 2. Águas de Lindóia, 1990. Anais. São Paulo, ACIESP, 71(1):142-150.

Martin, L.; Flexor, M.; Blitzkow, D. \& Suguio, K. 1985. Geoid changes indications along the Brazilian coast during the last 7.000 years. In: INTERNATIONAL CORAL REEF CONGRESS Tahiti, 1985. Proceedings. Tahiti, IGCP, 3: 8590.

Moraes Rêgo, L. F. 1932. Notas sôbre a geomorfologia de São Paulo e sua gênesis. São Paulo, Instituto Astronômico e Geográphico. 28p.

Navarra, C. T.; Furtado, V. V.; Eichler, B. B. \& Prado, O. R. 1980. Distribuição da matéria orgânica nos sedimentos marinhos costeiros e nos solos hidromórficos da orla litorânea do Estado de São Paulo. Bolm Inst. oceanogr., S Paulo, 29(2):267-270.

Petri, S. \& Suguio, K. 1973. Stratigraphy of the Iguape-Cananéia lagoonal region sedimentary deposits, São Paulo, Brazil - Part II : Heavy mineral studies, microorganisms inventories and stratigraphical interpretations. Bolm IG, Inst. Geociênc., Univ. S Paulo, 4: 7-85.

Ponçano, W. L. 1985. Sedimentação atual aplicada a portos do Brasil. Tese de doutorado. Universidade de São Paulo, Instituto de Geociências. 278p.

Ponçano, W. L. \& Fúlfaro, V. J. 1976. Sedimentação atual nas adjacências da Ponta de Itaipu e Baía de Santos: implicações na escolha de locais de lançamento de material dragado. In: CONGRESSO BRASILEIRO DE GEOLOGIA DE ENGENHARIA, 1. Rio de Janeiro, 1976. Anais. São Paulo, ABGE, 2:111-139.

Rodrigues, M. 1996. Sedimentação atual nas enseadas de Ubatumirim e Picinguaba, e plataforma interna adjacente, Ubatuba, Estado de São Paulo. Dissertação de mestrado. Universidade de São Paulo, Instituto Oceanográfico. $158 \mathrm{p}$.
Sadowsky, V. 1952. Observações sobre as modificações em curso na entrada de Cananéia, de sua Barra e da região adjacente. I. Desgaste das costas. n. 1 - Ponta da Trincheira (1952). Bolm Inst. oceanogr., S Paulo, 3(1/2):201-212.

Sadowsky, V. 1953. Modificações em curso na entrada da Barra de Cananéia. Bolm Inst. oceanogr., S Paulo, 4(1/2): 191-214.

Sadowsky, V. 1954. Novas contribuições ao estudo da entrada da Barra de Cananéia. Bolm. Inst. oceanogr., S Paulo, 5(1/2):151-178.

Souza, C. R. G. 1990. Considerações sobre os processos sedimentares quaternários e atuais na região de Caraguatatuba, litoral norte do Estado de São Paulo. Dissertação de mestrado. Universidade de São Paulo, Instituto Oceanográfico. $334 \mathrm{p}$.

Souza, L. A. P. 1995. A planície costeira Cananéia - Iguape, litoral sul do Estado de São Paulo: um exemplo de utilização de métodos geofísicos no estudo de áreas costeiras. Dissertação de mestrado. Universidade de São Paulo, Instituto Oceanográfico. 207p.

Suguio, K. \& Martin, L. 1976a. Mecanismos de gênese das planícies quaternárias do litoral do Estado de São Paulo. In: CONGRESSO BRASILEIRO DE GEOLOGIA, 29. Belo Horizonte, 1978. Anais. Belo Horizonte, SBG, 1:295-305.

Suguio, K. \& Martin, L. 1976b. Brazilian coastline quaternary formations: the State of São Paulo and Bahia littoral zone evolutive schemes. An. Acad. bras. Ci., 48:325-334.

Suguio, K. \& Martin, L. 1978. Quaternary marine formations of the state of São Paulo and southern Rio de Janeiro. In: INTERNATIONAL SYMPOSIUM ON COASTAL EVOLUTION IN THE QUATERNARY. São Paulo, 1978. Spec. Publ. São Paulo, IGCP/SBG. 55p.

Suguio, K. \& Petri, S. 1973. Stratigraphy of the Iguape-Cananéia lagoonal region sedimentary deposits, São Paulo, Brazil. Part I :Field observation and grain size analysis. Bolm IG, Inst. Geociênc., Univ. S Paulo, 4: 1-20. 
Suguio, K. \& Tessler, M. G. 1983. Intense coastal sedimentation and erosion in the Cananéia outlet, southern State of São Paulo, Brazil. Bolm Inst. oceanogr., S Paulo, 32(1):71-75.

Suguio, K.; Tessler, M. G.; Furtado, V. V.; Eesteves, C. A. \& Souza, L. A. P. 1987. Perfilagens geofisicas e sedimentação na área submersa entre Cananéia e Barra de Cananéia - SP. In: SIMPÓSIO SOBRE ECOSSISTEMAS DA COSTA SUL E SUDESTE BRASILEIRA: SÍNTESE DE CONHECIMENTOS, 1. Cananéia, 1987. Anais. São Paulo, ACIESP, 2: 234-241.

Taunay, A. d'E. 1922. Collectanea de mappas da cartographia paulista antiga abrangendo nove cartas, de 1612 a 1837, reproduzidas da collecção do Museu Paulista e acompanhadas de breves commentarios por Affonso d'Escragnolle Taunay. São Paulo, Companhia Melhoramentos. 7p. +9 mapas.

Tessler, M. G. 1982. Sedimentação atual na região lagunar de Cananéia-Iguape, Estado de São Paulo. Dissertação de mestrado. Universidade de São Paulo, Instituto de Geociências. 277p.
Tessler, M. G. 1988. Dinâmica sedimentar quaternária no litoral sul-paulista. Tese de doutorado. Universidade de São Paulo, Instituto de Geociências. 276p.

Tessler, M. G. \& Furtado, V. V. 1984. Dinâmica de sedimentação das feições de assoreamento da região lagunar de Cananéia-Iguape, Estado de São Paulo. Bolm Inst. oceanogr., S Paulo 32(2):117-124.

Tessler, M. G.; Suguio, K. \& Robilotta, P. R. 1987. Teores de alguns elementos traços metálicos em sedimentos pelíticos da superficie de fundo da região lagunar de Cananéia-Iguape. In: SIMPÓSIO SOBRE ECOSSISTEMA DA COSTA SUL E SUDESTE BRASILEIRA: SÍNTESE DOS CONHECIMENTOS. Cananéia, 1987. Anais. São Paulo, ACIESP, 2: 255-263.

(Manuscript received 01 October 1998; revised 15 December 1998; accepted 02 March 1999) 